\title{
Constraints and Prospects of Mechanized Processing of Forest Tree Seeds
}



\author{
${ }^{*}$ Federal College of Forest Resources Management, Sakponba Benin City, Nigeria \\ ${ }^{2}$ Moist Forest Research Station, Forestry Research Institute of Nigeria, Benin City, Nigeria \\ *Corresponding Author Email: adeleyeadegoke03@gmail.com
}

\begin{abstract}
Trees are generally propagated from seeds and the suitability and quality of the seeds have a big effect on the success of the plantations, afforestation and reforestation programmes established from their seedlings. In view of the fact that good forestry projects start with good seeds, the quality as well as quantity of tree seeds is very important. Processing of seeds is one of the main factors that determined the quality and quantity of seeds. However, processing of forest tree seeds in Nigeria and other developing countries has mostly been carried out using traditional methods which affects the quality of the seeds especially for large quantity of seeds. This work attempts to raise awareness on the need to mechanize processing of forest tree seeds so as to increase the quantity and quality of the seeds and to reduce the drudgery, time and health hazards involved in the common traditional methods of processing the seeds. Tree seeds are often regarded as inferior to crop seeds, a misnomer (mistaken belief) that needs to be rectified to promote tree planting.
\end{abstract}

DOI: $\underline{\text { https://dx.doi.org/10.4314/jasem.v25i4.24 }}$

Copyright: Copyright (C) 2021 Adeleye et al. This is an open access article distributed under the Creative Commons Attribution License (CCL), which permits unrestricted use, distribution, and reproduction in any medium, provided the original work is properly cited.

Dates: Received: 14 February 2021; Revised: 26 March 2021; Accepted: 12 April 2021

Keywords: Constraints, Forest Tree, Processing, Mechanization, Seeds

Forests have sustained human needs world over for centuries and people have harvested fuel wood, fodder, other plant materials, hunted wild animals for meat and grazed their livestock in forests (Mehta et al., 2008; Arjunan et al., 2005; Harris and Mohammed, 2003). Tewari, 2012 stated that millions of households in developing countries, Nigeria inclusive therefore depend on forests for its products and benefits which they also harvest, process and trade in to generate income. Forest has been known to be a source of livelihood all over the world particularly for resource poor people who are living close to and within the forests. It is the activities that generate food and income that can be used in purchase of other goods and services required for decent living. However, the increase in human density near and within the forested areas has been noted to contribute to forest degradation, loss of biodiversity and forest cover (Davidar et al., 2010; Karanth et al., 2006). Deforestation is one of the human activities that have striking effect on the forest and earth's environment, which is compensated by corresponding afforestation and reforestation efforts. In 2008, Oloyede reported that nearly $50 \%$ of the earth's land surface has been transformed by direct human action, such as deforestation with significant consequences on biodiversity, soil and climate. Thus, there is urgent need to plant and grow more trees because of the numerous contributions which play significant roles in food production, medicine as well as employment and income generation. So the drive to plant trees is on the increase as the values of trees and forest is being appreciated all over the world and has led to a marked increase in the demand for forest tree seeds and other planting materials in many countries.

Seeds, the only reproductive material in most of the forest tree species are critical for the production of seedlings, for natural regeneration and for future afforestation programmes in the country is losing diversity. Due to population explosion and other developmental activities, several forest tree species are getting threatened and hence ultimately affecting the seed source and its availability. Large quantities of forest tree seeds are needed every year to raise the nursery stock for propagating the desired plant species. For successful establishment of forest plantation, a plentiful supply of quality seed i.e., high in viability and vigour, is therefore one of the prerequisites, as majority of afforestation and agroforestry programmes depend on seed as a planting material. Continuing interest in making our country, Nigeria one of the least emitting Green House Gas emissions by increasing the forest cover brings the importance of forest seed to the forefront. Hence obtaining quality planting material and in heavy amounts from different forest tree species needs better understanding of seed genetics, collection, storage, 
processing, marketing and its, legislation. Hence, processing of forest tree seeds is exceptionally vital to achieve clean, pure seeds of high physiological quality (germinability) which can be stored and easily handled during succeeding processes, such as pretreatment, transport and sowing. Processing includes a number of handling procedures, where applicability differs according to fruit and seed type, condition of the fruits or seeds at collection and potential storage period. Well processed seeds provide seeds of highest quality which will result in trees of the highest value in the field. Seed with high physical quality is supposed to be whole, sound and expected to be of optimal size (as per the species).Processing of forest tree seeds manually has been prevalent in the developing countries. Manual methods such as pounding seeds in mortars (Fig. 1a), hitting bags of seeds with sticks (Fig. 1b), treading or rubbing on the floor with shoes or bare foot (Fig. 1c), hand picking, crushing using stones etc are not efficient most especially for large quantity of seeds. The continuous utilization of manual methods in processing of forest tree seeds can hamper the quality and quantity of seeds needed to achieve the afforestation and agroforestry programnme. On the other hand, the mechanical methods of processing forest tree seeds in most cases are not available for use or not even in existence. Consequently, it is very important to state that the processing of forest tree seeds using locally made machines would aid in the quality and quantity of the seeds, and also ease by reducing the processes involved using the traditional methods which is tedious and energy sapping, time consuming and low productivity, also has hazardous effect on human health. Therefore, the objective of this paper is to evaluate the constraints and prospects of mechanized processing of forest tree seeds in Nigeria.

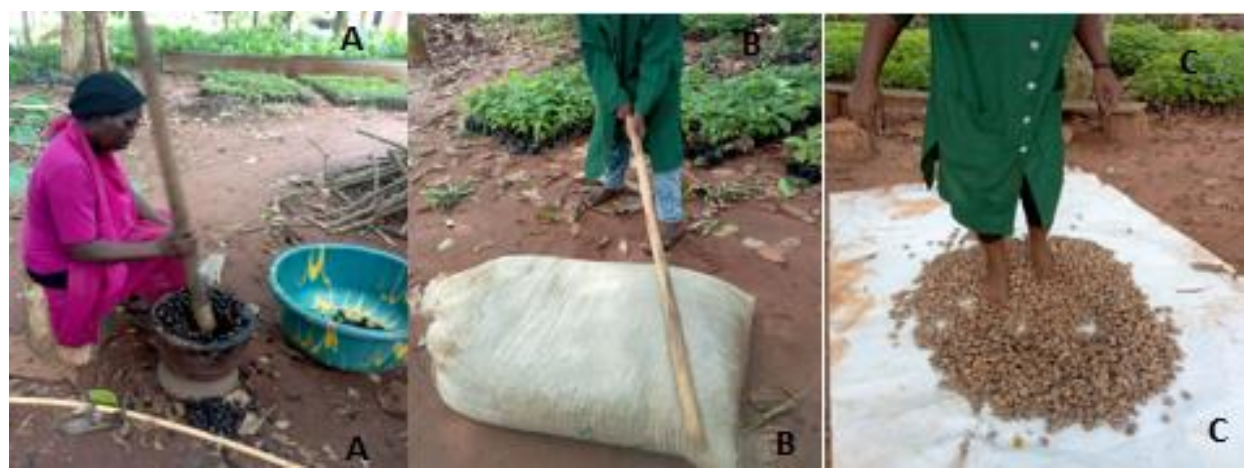

Fig 1: Manual processing of forest tree seeds at Moist Forest Research Station, Forestry Research Institute of Nigeria, Benin - City. (a) Pounding Gmelina arborea seeds in mortar; (b) hitting bag of Tectona grandis seeds with stick and, (c) rubbing Tectona grandis seeds on the floor with bare foot.

Processing of Forest Tree Seeds: Processing of forest tree seeds depends on the type and nature of fruits. Processing of forest tree seeds can be done using the following operations:

i. Sorting: Not all fruits collected in the field are mature or of good quality, fruits are therefore sorted according to their maturity. Mature fruits are separated and processed for seed extraction, fruits that are undeveloped or infected with insects and disease would be discarded whereas fruits that are not fully mature are separated and allowed to after-ripen. Afterripening is important, because extraction of seed from immature fruits can damage the seed. The process of sorting fruits for seed extraction is mostly done manually by handpicking after physical observation.

ii. Pre-cleaning: Pre-cleaning is the removal of larger debris such as leaves, twigs and empty fruits parts etc from fruits or seed lots before seed extraction and subsequent operations. In the field, pre-cleaning is undertaken primarily to reduce bulk during transport and storage. If bulk reduction has not been undertaken in the field, it may be relevant at the processing depot. Redundant bulk inevitably hampers the efficient use of processing equipment, simply because it adds to the volume to be processed. In some cases pre-cleaning may be necessary to remove material that may impede efficient extraction and subsequent cleaning. For example, twigs left with acacia pods to be threshed for seed extraction break down to size and weight similar to the seed during threshing. The twig fragments are very difficult to separate from the seed during the subsequent cleaning operation (ATSC, 1995). Furthermore, leaves, twigs or soil particles may carry fungal spores or other pathogens, which may infect the extracted seeds or germinating seeds and seedlings. An example of the latter is the needle cast disease that affects certain pines. Fungal spores of this pathogen are carried on the dry needles and may from there contaminate the seed lot. The sooner the needles are removed from the seed, the easier it is to control the disease. Pre-cleaning is usually done manually after 
arrival at the seed-processing depot. Manual precleaning of seed lots can be employed for smaller quantities. Large quantities of fruits are pre-cleaned mechanically e.g. on vibrating or oscillating screens or in tumblers. The design of pre-cleaning equipment depends on fruit and seed type and the character of debris (twigs, leaves, stones, soil etc.).

iii. Seed Extraction - Extraction refers to the procedure of physically releasing and separating the seeds from their enclosing fruit structure. The main rationale of extraction is to:

- $\quad$ Reduce bulk-The seeds typically make up 1$5 \%$ of the total fruit volume. Bulk reduction helps to reduce cost of storing and shipment.

- $\quad$ Ease handling- Seeds are normally tested, pretreated and sown individually, which makes their separation from the fruit necessary.

- Improve storability-Easily decomposable fruit parts such as the pulp of fleshy fruits or arils must be removed to avoid their decomposition during storage. Moisture contained in dry fruit types and cones may attract fungi and insects, especially if stored under ambient temperature. In addition, drying of seeds to safe moisture content becomes difficult if they are not extracted.

Seeds are extracted from most multiple-seeded dry fruits such as capsules, pods and follicles and from most fleshy fruit types. In single or few-seeded dry fruits like samaras and nuts, the whole fruit is normally stored and sown, although sometimes after removal of e.g. wings or other external structures. In a few fleshy fruits like Vitex parviflora, and arillate seeds of some Podocarpus spp. the whole fleshy unit may be dried and stored. In drupes, extraction is only partial as only the fleshy pulp is normally removed, the seed remaining within the dry endocarp. In multiple or compound fruits like Casuarina, Morus and Banksia, extraction is also only partial in the sense that the single-seeded fruits (samaras, achenes or nuts) are extracted from the compound bulky fruit structure. Extraction is usually undertaken prior to storage, but in some species it may be delayed until just before sowing or omitted altogether, e.g.:

(i) Where storability of non-extracted seeds is considerably better than that of extracted seeds.

(ii) Where labour requirement for extraction is so high that it outweighs possible gain from extraction, e.g. ease of handling and germinability.

(iii) Where storage facilities, shipment, transport or other handling procedures do not make extraction mandatory.

The method of seed extraction depends on the tree species and fruit type:
The dried fruit or pods of some tree species open readily to release their seed. To facilitate seed gathering for processing, the fruit or pods of these species are dried on big plastic sheets or tarpaulin under direct sunlight. Normally, 2-3 days of drying is enough. Rubbing and crushing the fruits will expedite seed extraction. The dried fruit or pods of other tree species open slowly over an extended period of time. To hasten seed extraction, fruits or pods of this type are placed in sacks and lightly beaten with a stick or firmly crushed before winnowing the seeds from the broken fruits or pods. Screens also can be used to separate seeds. For instance, sun-drying will cause pods of the mahoganies and eucalypts to crack and release the seeds.

$>\quad$ Some tree species, such as Gmelina arborea (gmelina), Azadirachta indica (neem), Tamarindus indica (tamarind) and Santalum spp. (sandalwoods) have large seeds in a fleshy pulp. This pulp will quickly rot, which may kill the seeds, so it is important to scrub and wash away all the fleshy material and juice, otherwise insects and fungi may infest the seed if the seeds are to be transported or stored. The fruits may be soaked in cool water a day or two to soften the pulp, then macerated and rinsed under running water or passed through a sieve. Fermentation usually should be avoided, as it may harm the seeds.

$>\quad$ The fruit of some tree species need to be scraped with an abrasive material such as sand or ash to remove the fleshy outer layer. The fruits of some species are simply broken open and the seeds removed. The seed of some species do not require extraction, rather the fruit are firmly rubbed together to remove the outer skin and other debris. While not truly extraction, this process serves the same purpose, preparing fruit for cleaning and grading. Fruit of Tectona grandis (teak) and Calamus species (rattans) are processed by this method. Some tree species such as monkeypod (Albizia saman), Elephant ear (Enterolobium cyclocarpum) have seeds in hard-toopen pods or pods with a gum or sticky substance around the seeds. Hard seed pods may need to be opened with a machete or broken with a hammer. Usually, gummy material can be removed by a brief water soak.

The processes of extracting tree seeds from their fruits or pods have been carried out largely using traditional methods. The operations of seed extraction can be achieved using machines (e.g. seed thrasher or thresher, depulping or macerating machine, hammer mill, mixer etc) most especially for large quantity seeds. However, all extraction methods should be conducted carefully to avoid damaging seed.

iv. De-winging-De-winging, in a broad sense, is removal of any dry seed appendage, including wings, spines, hairs, and some aril types. Seed (or fruit) wings 
do not obstruct germination, but may be inconvenient in handling. Accordingly, the main purpose of dewinging is to reduce bulk and ease handling during storage, pretreatment and sowing. In some instances wings, hairs or other appendices, which increase the surface area of the seed, tend to collect moisture and promote fungal attack. De-winging is often done as a routine before storage or shipment, while seeds sown immediately after collection, e.g. dipterocarps and other recalcitrant tree species, rarely have their wings removed. Wings are typical of indehiscent dry fruits like samaras of African Terminalia spp., Pterocarpus, Triplochiton, Heretiera, Kokoona, Casuarina and many others. Winged seeds occur in many Meliaceae (e.g. Cedrela, Chukrasia, Khaya, Swietenia) and Bignoniaceae (e.g. Markhamia, Tabebuia, Tecoma and Spathodea), and prevail in conifers. Most conifer seeds have wings that must be removed by hand rubbing, beating or trampling in sacks, moistening and raking, or treatment in de-winging machines where wings are abraded between brushes. Treatment must be done carefully to avoid injury to the seeds. During de-winging operation, the seeds are rubbed by revolving brushes against the wall of a cylinder consisting of wire mesh. Rotation speed, distance between brushes and cylinder, type of brushes and mesh wall of the cylinder can be adjusted according to seed type and wing or appendix to be removed (Karrfalt, 1992). Large winged seeds like Swietenia, Entandophragma or Triplochiton spp. are de-winged manually by breaking off the wing by hand or cutting it with secateurs. Unfortunately no mechanical dewingers yet devised are entirely satisfactory, yet hand methods are too expensive for large-scale use.

v. Cleaning-After extraction and possible dewinging, the seed lot typically consists of seeds mixed with inert matter such as twigs, leaf and fruit fragments, soil particles, empty and foreign seeds, dust, chaff and the like. The aim of seed cleaning is to eliminate all this foreign material to reduce bulk, improve storability and make seeds easier to handle during subsequent processes. The ideal cleaned seed lot consists of all viable seeds of the target species, and is free from any other matter. The degree to which this is achieved is called the purity, usually measured in percentage. A purity of $90 \%$ means that $90 \%$ is seed and $10 \%$ is other seed and inert matter. Some cleaning methods are also used during the process of grading or upgrading in which both germination and uniformity of the seed lot are increased by removing a fraction of seeds of the same species usually the smallest and those with no or poor viability. Basically, material can be separated from the seeds if it differs in physical characteristics like size, form or gravity. Thus seed cleaning is subject to the trivial precondition that the more the inert matter differs from the seeds in these physical characteristics, the easier it is to separate. And the more similar the impurities are to the seeds, the more difficult they are to eliminate. Variation in seed size and morphology of the seed adds another constraint to seed cleaning. The larger the variation in the seed lot, the more difficult it is to clean. The process of cleaning is also known as winnowing.

In its simplest form of winnowing, seeds are held in large flat baskets. The seeds to be cleaned are thrown up into the air, and the wind will then blow away light matter like dust, wings and leaf fragments, while the heavier seeds will fall back into the basket. This is the traditional way of cleaning grain and can be quite effective for small seed lots. Natural wind displacement can also be used by slowly pouring the un-purified seeds from a certain height into a pile, allowing the wind to blow away light matter while the seeds fall. Since natural wind velocity varies, the method is not always efficient. Cleaning large quantities of seeds is more efficiently done by mechanical equipment, especially where combined machines can be used for extraction and cleaning. In some combined machines the fruits can be fed in one end and the cleaned seed obtained in the other. In the mechanical form, winnowing works with an artificial and normally adjustable air stream. Table fans or vacuum cleaners (Gray, 1990) can create simple artificial air currents. More sophisticated cleaners use large stationary fans or propellers. The strength of the air current is adjusted according to seed type and debris. Many types of mechanical seed cleaners with different and replaceable screens are available.

vi. Grading-After cleaning, the seeds should be graded to separate good and poor seeds. It reduces the chances of diseases, quantity of seed to be procured as well as its cost. The cleaned seeds of some species may have wide variation in certain physiological or physical characteristics: maturity, viability, size, color, etc. These differences may affect seedling quality, the market demand for seed and the price of seed. In such situations, it is appropriate to grade seed according to relevant characteristics. Grading criteria will vary by species and local perceptions; and should be based on local experience and market specifications. During the grading process, any remaining empty, weak or damaged seeds and other debris in the seed lot should be discarded because these will not produce healthy seedlings. Any step in the processing procedure must be carefully adjusted to the particular fruit or seed type. Processing implies a risk of losing seeds both by under and over-treatment. Under-treatment may fail to achieve the desired result (e.g. insufficient extraction of seeds); over-treatment may damage the seeds with consequent loss of viability or reduced storability. Both under and over-treatment may influence the genetic composition of the seed lot. 
Constraints and Challenges: Processing of forest tree seeds has been mechanized in the developed countries. Despite the availability of mechanical operations elsewhere, forest tree seeds are still processed using traditional methods with little mechanization in the developing countries (Sarker and Erskine, 2002). Such technical constraints has affected and limited the quality and quantity of forest tree seeds, which most likely have contributed to the low rate of afforestation and establishment of forest plantation. As recent studies show that forests now occupy about 923,767 $\mathrm{km}^{2}$ or about 10 million hectares. This is about $10 \%$ of Nigeria's forest land area and well below FAO's recommended national minimum of $25 \%$ (Ladipo, 2010). The constraints to mechanization has been lack of skilled labour to operate such machinery, small farm sizes, unfavourable government policies and high cost of farm machinery. Apart from these constraints, the major constraint in the mechanization of processing forest trees seeds is the non-availability or non-existence of the machines and equipment (most especially locally made machines). However, the fact is that in most developing countries Nigeria inclusive, the number of scientists concerned with forest tree seeds is significantly lower than those involved in crop, fruits and vegetables seeds, especially mechanization of operations involved in the processing of forest tree seeds. Similarly, more research attention, innovation, technological advances and resources have been devoted to the mechanization of processing crop seeds. Research and development efforts aimed at mechanization options for processing forest tree seeds have not been effectively directed with a focus on identifying needs with the key stakeholders of forestry and manufacturers; rather inappropriate "solutions" have often been developed in isolation and have subsequently withered on the vine after the fanfare of initial promotion (Starkey, 1988).

Prospects: Trends in mechanization worldwide clearly show that there are strong correlations between economic growth and mechanization (FAO and UNIDO, 2008). Farm mechanization has been helpful to bring about significant improvement in agricultural productivity. Thus, there is the need for mechanization of operations in processing of forest tree seeds. The factors that justify the mechanizing of processing forest tree seeds in the country can be numerous. Firstly, the timeliness of operations in processing seeds mechanically has assumed greater significance in obtaining optimal yields from different tree seeds. Secondly, the quality and precision of the operations are equally significant for realizing higher yields. The various seed processing operations such as precleaning, seed extraction, winnowing, sorting etc require a high degree of precision to increase the efficiency of the inputs and reduce losses. However, when such operations are performed through indigenous methods, their efficiency is reduced. Thirdly, mechanization of processing forest tree seeds offers a better chance for reducing losses of viable tree seeds during processing, thereby increasing the number of possible tree seedlings and trees to be planted for forest plantation. Fourthly, the use of mechanization for processing tree seeds enlarges the employment opportunities through increase in area earmarked for the yearly establishment of forest plantation. On the other hand, displacement of human labour does take place and demand for semi-skilled labour in place of unskilled labour is increased. Also, the drudgery for human labour is reduced and prevents hazardous effects on human health, thereby increasing the interest in processing forest tree seeds.

Conclusion: The boost in economic growth as seen in most developed countries through forestry could also happen in Africa and Nigeria if the stakeholders in the establishment of forest plantation could be helped to intensify their activities through increasing levels of mechanization in forestry operations most especially in processing of forest tree seeds. Local manufacture of locally adapted mechanization inputs should be encouraged and facilitated, rather than dependence on importation. Consequently, mechanization of processing forest tree seeds must meet the needs efficiently, effectively and result in improved seeds and reduced drudgery, as well as contributing to the development of the forest sector.

\section{REFERENCES}

Arjunan, M; Puyravaud, JP; Davidar, P (2005). The Impact of Resource Collection by Local Communities on the Dry Forests of the KalakadMundanthurai Tiger Reserve, India. Trop. Ecol.46: 135 - 143.

ATSC (1995). Operation Manual. Australian Tree Seed Centre. CSIRO, Canberra.

Davidar, P; Sahoo, S; Mammen, PC; Acharya, P; Puyravaud, JP; Arjunan, M; Garrigues, JP; Roessingh, K (2010). Assessing the Extent and Causes of Forest Degradation in India: Where do we stand? Bio. Conserve.143: $2937-2944$.

FAO \& UNIDO. (2008). Agricultural Mechanization in Africa. Time for Action: Planning Investment for Enhanced Agricultural Productivity. Report of an Expert Group Meeting Jointly held by FAO and UNIDO in Vienna on 29-30 Nov. 2007. 
Gray, R (1990). Professional Seed Collection. In: Sowing the Seeds. Direct Seeding and Natural Regeneration Conference. Greening Australia Proceedings pp 135-140.

Harris, F; Mohammed, S (2003). Relying on Nature: Wild Foods in Northern Nigeria. Ambio 32: 24-29.

Karanth, KK; Curran, LM; Reuning-Scherer, JD (2006). Village Size and Forest Disturbance in Bhadra Wildlife Sanctuary, Western Ghats, India. Biol. Conserve.128: $47-157$.

Karrfalt, RP (1992). Increasing Hardwood Seed Quality with Brush Machines. Tree Planters Notes. 3:2, 33 - 35. USDA Forest Service.

Ladipo, D (2010). The State of Nigeria's Forests. IITA Res. Develop. Rev. Bull.4. Retrieved from http://r4dreview.org/2010/04/thestate-ofnigeriaforests/

Mehta, VK; Sullivian, PJ; Walter, MT; Krishnaswamy, J; Degloria, SD (2008). Ecosystem Impacts of Disturbance in a Dry Tropical Forest in Southern India. Ecohydrology, 1: 149 - 160.
Oloyede, IO (2008). Afforestation and Reforestation: The Unilorin Experiment. A Presentation at the High Level Technical Workshop on Afforestation and Climate Change in Africa. pp. 23.

Sarker, A; Ersine, W (2002). Lentil Production in the Traditional Lentil World. In: Brouwer, J.B. (ed.) Proceedings of Lentil Focus 2002, Horsham, Victoria, Australia. Pulse Australia, Sydney, pp. 35-40.

Starkey, P (1988). Deutsches Zentrum für Entwicklungstechnologien - GATE. In AnimalDrawn Toolcarriers: Perfected yet Rejected: A Cautionary Tale of Development; Deutsche Gesellschaft für Technische Zusammenarbeit (GTZ) GmbH: Wiesbaden, Germany; p. 161.

Tewari, DD (2012). Promoting Non Timber Forest Products (NTFPs) to Alleviate Poverty and Hunger in Rural South Africa: A Reflection on Management and Policy Challenges. Afr. J. Business Manage .6(47): 11635 - 11647. 